\title{
Clinico-aetiological profile of fever of unknown origin (FUO) in children in a single centre
}

\author{
Sujatha Ramabhatta ${ }^{1}$, Pushpalatha Kariyappa $^{2}$, Hareesh Sanikam ${ }^{3}$, Udaya Kumar S Savan Pujar $^{5}$, \\ Pavan Kittagaly ${ }^{6}$
}

Sri Lanka Journal of Child Health, 2019; 48(2): 117-120

\begin{abstract}
Objective: To identify the aetiology of children presenting with fever of unknown origin (FUO).
\end{abstract}

Method: A prospective study of children between 6 months to 18 years admitted for FUO at Employees State Insurance Corporation Medical College and Post Graduate Institute of Medical Science and Research, Bangalore, India, from March 2017 to February 2018 were included. All children were subjected to detailed history, clinical examination and baseline investigations. Further investigations were done based on the presumptive diagnosis

Results: Of the 3656 children admitted to the paediatric ward for various diseases during the study period, 24 fulfilled the inclusion criteria. Children between 12-18 years constituted the majority. Infections were the commonest cause of FUO (70.8\%). Among them tuberculosis was the commonest $(\mathrm{n}=11)$. Mortality was $8.3 \%$

Conclusions: In our study, infections were the cause of FUO in $70.8 \%$ and tuberculosis was the commonest infectious cause.

DOI: http://dx.doi.org/10.4038/sljch.v48i2.8703

(Keywords: FUO, infection, tuberculosis)

\section{Introduction}

The term 'fever of unknown origin' (FUO) was first described by Petersdorf and Beeson in the adult population ${ }^{1}$. It is best reserved for children

${ }^{1}$ Associate Professor, ${ }^{2}$ Professor and Head,
${ }^{3}$ Assistant Professor, ${ }^{4}$ Professor, ${ }^{5}$ Junior Resident,
Department of Pediatrics, ESICMC \& PGIMSR,
Rajajinagar, Bengaluru, India, ${ }^{6}$ Intern, Sapthagiri
Institute of Medical Sciences and Research Centre,
Bengaluru, India
*Correspondence: dr.pushpalathaanil@yahoo.in
iD https://orcid.org/0000-0001-7669-7746
(Received on 19 May 2018: Accepted after revision on 20 July 2018)

The authors declare that there are no conflicts of insterest Personal funding was used the project. with fever documented by a health care provider for which a cause could not be identified after three weeks of evaluation as an outpatient or after one week of evaluation in a hospital ${ }^{2}$.

\section{Objective}

To identify the aetiology of children presenting with FUO

\section{Method}

A prospective observational study was conducted from March 2017 to February 2018, in the Paediatric Department of Employees State Insurance Corporation Medical College (ESICMC) and Post Graduate Institute of Medical Science and Research (PGIMSR), Bangalore, India. All children between 6 months to 18 years who had fever of 3 weeks at or after admission, with normal first line investigations were included in the study. A detailed clinical examination was performed. First line investigations like complete haemogram, routine urine test and urine culture, blood culture, Mantoux test, chest x-ray, malarial parasite (MP) smear, Widal test, leptospira antibody and Weil Felix tests were done in all patients. Additional tests like sonogram, serology, antinuclear antibody (ANA) profile, imaging studies, lumbar puncture, fine needle aspiration cytology (FNAC) of lymph node, bone marrow aspiration, culture and biopsy and bronchoscopy were done wherever indicated.

\section{Results}

During the study period, out of 3656 children admitted to the paediatric ward, twenty four children, who fulfilled the inclusion criteria of FUO, were enrolled for the study. Adolescents in the age group of 12-18 years constituted the majority $(n=14,58 \%)$. Four children were below 5 years (among them one was an infant) and six were aged between 5-12 years. No sex preponderance was noted with the male to female ratio 1.18:1. The duration of fever ranged from 15 days to 4 months at admission with a mean of 4.6 weeks. Eleven (45\%) children had fever of 3 weeks duration whilst $8(33.3 \%)$.children had fever of more than 1 month. In addition to fever, other symptoms noted were cough $(n=5)$, joint pains $(n=5)$, loss of weight $(n=8)$, loss of appetite $(n=4)$, headache, vomiting, weakness and convulsions $(n=4)$ and abdominal pain $(n=2)$. All the children had received a course of antibiotics and four children had received 
antimalarial drugs before admission on an outpatient basis. History of contact with tuberculosis was elicitable in $3(12.3 \%)$ and with pets at home in $2(8.3 \%)$.

Four children weighed below the third percentile. Pallor was found in $10(41 \%)$ children, significant cervical lymphadenopathy in 5 (20.8\%), hepatomegaly in $10(41 \%)$ and splenomegaly in 7 $(29.2 \%)$ children. Detailed systemic examination was normal in the majority of $\mathrm{t}$ children.

Baseline investigations revealed anaemia in $50 \%$ of the children with a mean haemoglobin of $9.9 \mathrm{~g} \%$ varying from $6.9-13.5 \mathrm{~g} \%$. Pancytopenia was noted in three $(12.5 \%)$ children, erythrocyte sedimentation rate (ESR) was raised in $17(70 \%)$ ranging from $35-120 \mathrm{~mm}$ in the first hour, and the C-reactive protein (CRP) was positive in $8(33.3 \%)$ children.

Mantoux test was positive in eight children. Microbiological confirmation of tuberculosis using Zeel-Nielson staining or Cartridge Based Nucleic Acid Amplification Test (CBNAAT) for acid fast bacillus was positive in 3 children. Computerized tomography (CT) of thorax and abdomen was done in 12 children and showed hilar adenopathy in 7 , lung nodule with splenomegaly in one, hepatomegaly with multiple haematomas in the IV segment of the liver in one and was normal in the other three. On 2D Echocardiography, one child showed vegetations, and the other had pericardial effusion.

Aspiration cytology of lymph node revealed reactive lymphadenitis in 4 children and one child had necrotizing granuloma. Bone marrow examination done in 2 children showed evidence of histiocytic macrophages in a normal marrow.

The aetiology of FUO was categorized into infections $(n=17,70.8 \%)$, malignancy $(n=2,8.3 \%)$, connective tissue disorders $(\mathrm{n}=1,4.1 \%)$, miscellaneous $(n=2,8.3 \%)$ and undiagnosed $(n=2$, $8.3 \%$ ) as shown in Table 1.

Table 1: Aetiology of FUO in our study $(n=24)$

\begin{tabular}{|l|c|}
\hline \multicolumn{1}{|c|}{ Diagnosis } & No. (\%) \\
\hline Tuberculosis & $11(45.8)$ \\
\hline Enteric fever & $02(08.3)$ \\
\hline Rickettsial fever & $01(04.2)$ \\
\hline Plasmodium vivax malaria & $01(04.2)$ \\
\hline Infective endocarditis & $01(04.2)$ \\
\hline Hepatic haematoma & $01(04.2)$ \\
\hline HLH & $02(08.3)$ \\
\hline Systemic lupus erythematosus & $01(04.2)$ \\
\hline Reactive arthritis & $01(04.2)$ \\
\hline Subcutaneous panniculitis & $01(04.2)$ \\
\hline Undiagnosed & $02(08.3)$ \\
\hline HLH:Haemophagocytic lymphohistiocytosis
\end{tabular}

HLH: Haemophagocytic lymphohistiocytosis

The commonest infective cause for FUO was tuberculosis $(\mathrm{n}=11,45 \%)$ with pulmonary tuberculosis in 4 and extra-pulmonary $\mathrm{TB}$ in 7 (TBM in 3, Lymph node tuberculosis in 3, disseminated tuberculosis in 1). Out of the two undiagnosed children, one child improved after 25 days of fever with symptomatic treatment and another child died at the end of three weeks with sudden onset of multi-organ dysfunction.

The diverse aetiologies of FUO in various studies are shown in Table 2.

Table 2: Aetiologies of FUO in various studies

\begin{tabular}{|l|c|c|c|c|c|c|}
\hline Study & $\begin{array}{c}\text { No. of } \\
\text { cases of } \\
\text { FUO }\end{array}$ & $\begin{array}{c}\text { Infection } \\
\mathbf{( \% )}\end{array}$ & $\begin{array}{c}\text { Connective } \\
\text { tissue } \\
\text { diseases } \\
\mathbf{( \% )}\end{array}$ & $\begin{array}{c}\text { Malignancy } \\
\mathbf{( \% )}\end{array}$ & $\begin{array}{c}\text { Miscellaneous } \\
\mathbf{( \% )}\end{array}$ & $\begin{array}{c}\text { Undiagnosed } \\
\mathbf{( \% )}\end{array}$ \\
\hline Present & 24 & 70.8 & 04.1 & 08.3 & 08.3 & 08.3 \\
\hline Landge A A et al & 49 & 79.0 & 14.0 & 0.0 & 06.1 & 12.0 \\
\hline Govindarajulu S et al & 120 & 69.1 & 05.0 & 16.7 & 05.8 & 03.4 \\
\hline Joshi et al & 49 & 69.4 & 02.1 & 12.2 & 04.1 & 12.2 \\
\hline Chantada et al & 113 & 36.3 & 13.2 & 10.0 & 22.0 & 19.5 \\
\hline Cogulu et al ${ }^{13}$ & 80 & 57.7 & 06.3 & 02.5 & 20.0 & 12.5 \\
\hline Bakasvilli et al & 52 & 61.5 & 04.0 & 04.0 & 17.3 & 13.5 \\
\hline Hashan et al & 127 & 36.2 & 10.2 & 29.9 & 7.87 & 15.8 \\
\hline Ching-Yi Cho et al & 126 & 27.0 & 12.7 & 16.6 & 19.8 & 23.8 \\
\hline Ya-Li Chien et al ${ }^{14}$ & 93 & 37.6 & 14.1 & 17.2 & 16.1 & 15.1 \\
\hline
\end{tabular}

Definitive diagnosis of TB based on the gold standard was arrived at in $8(33.3 \%)$ children. Three had microbiologically confirmed tuberculosis, 1 had urine culture positive for Klebsiella, 2 had HLH based on bone marrow examination, one had SLE based on ANA titres and one had infective endocarditis based on vegetations in the 2D Echo. Invasive investigations like bone marrow, lumbar puncture, FNAC, pleural 
aspiration and broncho-alveolar lavage (BAL) was done in a total of eight $(33.3 \%)$ children

Twenty (83.3\%) children recovered from the illness and one child diagnosed as subcutaneous panniculitis was lost to follow up. Two $(8.3 \%)$ children died in the study group out of which one was diagnosed as hepatocellular $\mathrm{T}$ cell lymphoma with haemophagocytic lymphohistiocytosis (HLH) and the other was undiagnosed. One child diagnosed as $\mathrm{T}$ cell lymphoma is currently on chemotherapy.

\section{Discussion}

FUO in children remains a diagnostic challenge for pediatricians. The aetiology of FUO varies depending on the geographical location, economy of the region studied, presence of vectors of infection, referral patterns, age of children, time of the study and the availability of diagnostic tests ${ }^{3}$. The incidence of FUO is around $0.5-3 \%$ in various studies $^{2}$. Our study showed an incidence of $0.6 \%$ similar to a study by Chouchane $\mathrm{S}$ et al which showed an incidence of $1.02 \%{ }^{4}$. Majority of children in the study group were adolescents (58\%) similar to a study by Bakashvilli et al where they constituted $87 \%$. The mean duration of fever in our study was 34 days with the majority (45\%) having fever of 21 days. Sixteen percent had fever for more than 2 months. This was similar to Chouchane S et al and Ching Yicho et al who had a mean fever duration of 30 days and fever of more than 60 days in $6.3 \%{ }^{6,7}$.

Aetiology of FUO is broadly classified as infectious, connective tissue disorders, malignancies and miscellaneous. Infections are the main cause for FUO constituting $60-70 \%{ }^{8}$. In our study they accounted for $70.8 \%$ similar to studies by Landge A A et al (79\%), Santosh G et al $(69.1 \%)$ and Joshi $N(69 \%)^{9,10,11}$. Table 2 shows the percentages of various causes in different studies. Tuberculosis constituted the majority of infections $(45 \%)$ in our study, similar to a study by Chantada et al and A A Landge et al (35\%) ${ }^{6,9}$. However Joshi $\mathrm{N}$ et al and Santosh $\mathrm{G}$ et al have documented enteric fever as the commonest cause of FUO in their studies, while Ching Yicho et al have documented Ebstein Barr virus and cytomegalovirus as the commonest aetiological factor. In our set up, enteric fever is a common infection diagnosed by cultures early in the course of illness. Hence not many cases of enteric fever pose a diagnostic challenge as FUO and also, our study group excluded children with fever of less than three weeks.

Definitive diagnosis of FUO was made in $33.3 \%$ as against a study by Landge A A et al which showed definitive diagnosis in $55 \%$. Diagnosis was established in two thirds of the cases by noninvasive methods similar to the study by Rasha AH et al. showing that a good history and relevant investigations help in reaching the diagnosis ${ }^{12}$. All children diagnosed as infections recovered. The mortality in our study was $8.3 \%$.

FUO in children poses a challenge to paediatricians. The aetiology varies depending on the geographical factors and economy of the nation. Infections still remain predominant cause of FUO in developing nations. Diagnosis can be established in the majority of the cases by noninvasive methods. Tuberculosis continues to be the leading cause of FUO among children. CT of thorax and abdomen has emerged as an important diagnostic tool in children with FUO.

\section{Conclusions}

In our study, infections were the cause of FUO in $70.8 \%$ and tuberculosis was the commonest infectious cause.

\section{References}

1. Petersdorf RG, Beeson PB. Fever of unexplained origin: report on 100 cases. Medicine Baltimore 1961;40:1-30 https://doi.org/10.1097/000057921961020 00-00001

2. Nield LS, Kamat D. Fever. In Kleigman RM, Stanton BF, St Geme JW, Schor NF, Behrman RE, Nelson Textbook of Pediatrics. $20^{\text {th }}$ ed. Philadelphia, PA: Saunders Elsevier: 2016: 1277-87.

3. Chow A, Robinson JL. Fever of unknown origin in children: a systematic review; World Journal of Pediatrics 2011; 7(1):510. https://doi.org/10.1007/s12519-011-02405

PMid: 21191771

4. Chouchane S, Chouchane $\mathrm{CH}$, Ben Meriem CH, Seket B, Hammami S, Nouri $\mathrm{S}$ et al. Prolonged fever in children. Retrospective study of 67 cases. Archives de Pediatrie 2004; 11(11):1319-25 https://doi.org/10.1016/S0929693X(04)00 457-9

5. Bakashvili LZ, Makhviladze MA, Pagava EK, Pagava KI. Fever of unknown origin in children and adolescents in Georgia: a review of 52 patients. Georgian Medical News 2006; 135:66-9 
6. Chantada G, Casak S, Plata JD, Pociecha J, Bologna R. Children with fever of unknown origin in Argentian: an analysis of 113 cases. Pediatric Infectious Disease Journal 1994; 13(4):260-3 https://doi.org/10.1097/000064541994040 00-00003

PMid: 8036040

7. Yicho C, Gong Wu K. Clinical analysis of fever of unknown oprigin in children - A 10 year experience in a northern Taiwan Medical Centre. Journal of Microbiology, Immunology and Infection 2017; 50(1):405 https://doi.org/10.1016/j.jmii.2015.01.001 PMid: 25735796

8. Singhal T,Lodha R, Kabra SK. Infections and infestations-Paul VK, Bagga $\mathrm{A}$ in Ghai Essential Pediatrics, $8^{\text {th }}$ edition 2013,CBS Publsihers, New Delhi:211-12.

9. Landge A A, Singhal T. Aetiology of fever of unknown origin from Mumbai, India; Indian Pediatrics 2018; 55(1):71-2 https://doi.org/10.1007/s13312-018-12343

PMid: 29396941

10. Govindarajulu S, Kalyanasundaram K, Pyarejan K S,Venkatswamy S. Clinical profile and aetiological spectrum of fever of unknown origin in children aged 2 months to 12 years; International Journal of Contemporary Pediatrics.2017; 4(1):62-7
11. Joshi N, Rajeshwari K, Dubey AP, Singh $\mathrm{T}$, Kaur R. Clinical spectrum of fever of unknown origin among Indian children. Annals of Tropical Pediatrics.2008; 28(4): 261-6 https://doi.org/10.1179/146532808X37541 3

PMid: 19021941

12. Hassan RH, Fouda A E, Kandil S M. Fever of unknown origin in children : a 6year -Experience in a tertiary Egyptian Hospital; International Journal of Health Science (Qassim) 2014, 8(1):13-19 https://doi.org/10.12816/0006067

13. Ya-Li Chien, F-L Huang, C-M Huang, Po$\mathrm{Y}$ Chen : Clinical approach to fever of unknown origin in children. Journal of Microbiology, Immunology and Infection 2015.

https://doi.org/10.1016/j.jmii.2015.08.007

14. Cogulu O, KoturogluG, Kurugol Z, Ozkinay F, Vardar F, Ozkinay C. Evaluation of 80 children with prolonged fever. Pediatrics International 2003 45(5):564-9 https://doi.org/10.1046/j.1442200X.2003.0 1793.x

PMid: 14521533 